\title{
Spirituality Scale Ceiling Effects and Near-Death Experiences: An Exploratory Study
}

\author{
Ryan A. Rominger, Ph.D. \\ Institute of Transpersonal Psychology
}

\begin{abstract}
A common theme noted among near-death experiencers (NDErs) is the affirmation of increased spirituality after their near-death experiences (NDEs). This study focused on the question of whether the Human Spirituality Scale (HSS), a commonly used spirituality measure, would exhibit a ceiling effect among NDErs. Thirty-seven participants from eight countries participated in the online study. HSS scores were compared with NDE Scale (Greyson, 1990) scores and demographic information. Results revealed no ceiling effect but revealed a positive correlation between the HSS and the NDE Scale. Additionally, exploratory post-hoc analysis was conducted on participant subgroups, comparing males and females and participants from India and the United States. Finally, preliminary findings regarding four NDErs self-identified as atheist/ agnostic are described.
\end{abstract}

KEY WORDS: Spirituality Scale, Near-Death Experience Scale, ceiling effect, atheist/agnostic, cross-cultural

In this article, I explore the use of spirituality scales with individuals who have had near-death experiences (NDEs). Since several of the first prominent writings on NDEs by then-medical-student Raymond Moody (1975) and later by academics and scholars (for example, Greyson \& Flynn, 1984; Ring, 1980a, 1984; Sutherland, 1992), researchers have been prolific in their reports of changes in religiosity and spirituality among near-death experiencers (NDErs; Fenwick \&

Ryan A. Rominger, Ph.D., is an Assistant Professor at the Institute of Transpersonal Psychology. The author thanks ITP for the faculty grant that made the first phase of this study possible and is grateful to Janice Miner Holden for her encouragement and editorial assistance without which this article may not have come to fruition. Reprint requests should be addressed to Dr. Rominger at Institute of Transpersonal Psychology, 1069 E. Meadow Circle, Palo Alto, CA 94303; email: rrominger@itp.edu. 
Fenwick, 1996; Greyson \& Bush, 1992; Groth-Marnat \& Summers, 1998; Holden, Greyson, \& James, 2009; Musgrave, 1997; Ring, 1980b; Sahlman \& Norton, 1998; Twemlow \& Gabbard, 1984). However, researchers have not standardized specific instruments to assess spirituality in the NDE population. Certain religiosity and/or spirituality instruments may or may not be appropriate for use with NDErs. Possible factors in inappropriate instruments include the use of offputting language or of too narrow a definition of spirituality to assess the dynamic changes that reportedly occur after experiences such as NDEs.

As a concrete example, I encountered a potential ceiling effect within my own research on integration of the aftereffects of an NDE (Rominger, 2009). I believed that the measure I utilized, the Human Spirituality Scale (HSS; Wheat, 1991), was not flexible enough or did not have a broad enough range for response and, thus, exhibited a ceiling effect. A ceiling effect occurs when a cluster of participants score near the topmost level of the scale, thus rendering further differentiation among participants impossible. In the case of my earlier research, most individuals who reported a pleasant core NDE scored at the top levels of the HSS at the pre-test and both post-tests, resulting in (a) little demonstrable change throughout the study, and (b) scores comparable to, and in most cases higher than, what Luther Wheat (1991) called a "high spirituality" group.

The current study is the first phase of a larger study investigating the scoring of individuals on various religiosity and spirituality scales who themselves report having had NDEs. This phase of the study included administration of the HSS, the Near-Death Experience Scale (NDE Scale; Greyson, 1983, 1990), and a demographics survey to selfidentified NDErs. The next phase, for which I am currently collecting data, focuses on particular spiritual qualities among NDErs and, thus, will include administration of MacDonald's (1997) Expression of Spirituality Inventory (ESI) to self-identified NDErs. Through these progressive stages I hope to better understand (a) the existence of a ceiling effect when using the HSS with the NDEr population (Phase 1), and (b) whether factors other than general spiritual orientation are more appropriate for measure when conducting research within the NDEr population (Phase $1 \& 2$ ). Specific goals for this first study included:

1. To explore presence of a ceiling effect on the HSS, and

2. To explore the relationship between the NDE Scale and the HSS. 


\section{Method}

This study was approved by the Research Ethics Committee at the Institute of Transpersonal Psychology.

\section{Participants}

I recruited participants through three main methods. One method was through online social networking sites. Invitations were posted, where appropriate and welcomed, through sites such as Facebook, MySpace, blogs, and websites focused on NDErs. Additionally, I ran an ad through the Facebook website from November 3, 2009 through December 3, 2009. A second recruitment method was through the International Association for Near-Death Studies (IANDS), especially during the 2009 IANDS Annual Conference in San Diego, CA. A third method was through snowball recruitment strategies, wherein I invited participants to invite others (or provide names of individuals) they knew who reported having had an NDE. I made every effort to include individuals from diverse backgrounds, both within the U.S. and internationally. With the intent of eliminating attempted duplicate entries, I did not accept multiple submissions from the same IP address and computer. As incentive to participate, I offered one iPod shuffle to the participant who completed all measures and who was selected through a random selection raffle process.

Of 83 individuals who started the online assessments, 45 completed the full set of questionnaires and reported having had an NDE. I used both quantitative and qualitative data to determine presence of an NDE. As Greyson (1983) had suggested, I omitted from the study any participants who scored below 7 on the revised NDE Scale (Greyson, 1990). In addition, among respondents who scored 7 or higher, I omitted from the study those whose narratives indicated they had not actually had an NDE. A total of eight respondents were thus omitted. Remaining respondents - those who had completed all questionnaires, scored 7 or higher on the NDE Scale, and provided narratives descriptive of NDEs - totaled 37. Average participant age was 32.65 , with a range of 18-62, and average age at time of NDE was 19.41—roughly 13 years before the study. Additional demographics are summarized in Table 1. Although these demographics may seem highly detailed, as part of a diversity movement within academia I would like to encourage and report more demographic statistics than less, as I believe it contributes to a broader picture of all participants, orienting readers to the diversity within the participant population. 
Table 1. Demographic Statistics

\begin{tabular}{|c|c|c|}
\hline & $N$ & $\%$ \\
\hline Sample population & 37 & 100 \\
\hline India & 19 & 51.4 \\
\hline United States & 12 & 32.4 \\
\hline Australia & 1 & 2.7 \\
\hline Canada & 1 & 2.7 \\
\hline Mexico & 1 & 2.7 \\
\hline Nigeria & 1 & 2.7 \\
\hline South Africa & 1 & 2.7 \\
\hline Ukraine & 1 & 2.7 \\
\hline \multicolumn{3}{|l|}{ Recruitment site/means } \\
\hline Facebook & 22 & 59.5 \\
\hline Craigslist & 3 & 8.1 \\
\hline General internet/email & 9 & 24.3 \\
\hline Personal Contact & 3 & 8.1 \\
\hline \multicolumn{3}{|l|}{ Abled / Disabled } \\
\hline Disabled / Differently Abled & 11 & 29.7 \\
\hline Able bodied & 26 & 70.3 \\
\hline \multicolumn{3}{|l|}{ Income } \\
\hline$\leq \$ 25,000$ & 13 & 35.1 \\
\hline$\$ 25,001-50,000$ & 13 & 35.1 \\
\hline$\$ 50,001-125,000$ & 9 & 24.3 \\
\hline$\geq \$ 125,001$ & 2 & 5.4 \\
\hline \multicolumn{3}{|l|}{ Number supported on income } \\
\hline 1 & 6 & 16.2 \\
\hline 2 & 10 & 27 \\
\hline 3 & 8 & 21.6 \\
\hline 4 & 8 & 21.6 \\
\hline 5 & 3 & 8.1 \\
\hline 6 & 1 & 2.7 \\
\hline$\geq 10$ & 1 & 2.7 \\
\hline \multicolumn{3}{|l|}{ Education } \\
\hline High school & 3 & 8.1 \\
\hline Some college & 6 & 16.2 \\
\hline Associates degree & 1 & 2.7 \\
\hline Bachelor's degree & 13 & 35.1 \\
\hline Master's degree & 11 & 29.7 \\
\hline Doctoral degree & 1 & 2.7 \\
\hline Post-doctoral studies & 2 & 5.4 \\
\hline
\end{tabular}




\begin{tabular}{lcc}
\hline & $N$ & $\%$ \\
\hline Sex & 17 & \\
Female & 20 & 45.9 \\
Male & & 54.1 \\
& & \\
Gender ${ }^{1}$ & 17 & 45.9 \\
Feminine & 19 & 51.4 \\
Masculine & 1 & 2.7 \\
Intersex & 1 & 2.7 \\
Gender fluid & & \\
Sexual orientation & & 89.2 \\
Heterosexual & 33 & 2.7 \\
Mostly heterosexual with occasional & 1 & 2.7 \\
$\quad$ non-hetero interests & & 2.7 \\
Bisexual & 1 & 2.7 \\
Pansexual & 1 & \\
Questioning & 1 & \\
& & \\
\hline
\end{tabular}

${ }^{1}$ The question on gender allowed a participant to "choose all that apply." Thus, the $N$ is larger than 37. The participants who chose intersex and gender fluid were not the same individual.

Because this was a study on spirituality and religiosity among NDErs, it seemed important to provide an in-depth demographic overview of participants regarding this domain. Participants responded to instrument items about their religious/spiritual upbringing, current religious/spiritual beliefs, and perceived difference between the two. Responses regarding upbringing and current religious affiliation are summarized in Table 2. I invite readers to note the variety of religious traditions represented in the "Upbringing" category as well as how religious affiliation changed over time. Responses regarding selfreported levels of spirituality/religiosity are summarized in Table 3. I invite readers to note how religiosity/spirituality shifted over time, with more participants reporting current beliefs falling within the range of moderately to very religious/spiritual. 
Table 2. Religion / Spirituality Demographics ${ }^{1}$

\begin{tabular}{|c|c|c|}
\hline & $\begin{array}{c}\text { Upbringing } \\
n\end{array}$ & $\begin{array}{c}\text { Current } \\
n\end{array}$ \\
\hline Atheist / Agnostic & & 4 \\
\hline Buddhist & 1 & 1 \\
\hline Christian & $(25)$ & (13) \\
\hline Catholic & 12 & 5 \\
\hline Christian Orthodox & 2 & 5 \\
\hline Protestant & 11 & 3 \\
\hline Confucian & 1 & \\
\hline Cosmic Energy & & 1 \\
\hline Eclectic Spirituality but not religious & 1 & 3 \\
\hline Hindu & (15) & (8) \\
\hline Shaivism & 3 & 3 \\
\hline Shaktism & 1 & \\
\hline Smartism & 1 & \\
\hline Vaishnavism & 1 & \\
\hline Other & 9 & 5 \\
\hline Jewish & (1) & (2) \\
\hline Conservative & & 1 \\
\hline Kabbalah & 1 & 1 \\
\hline Muslim & $(2)$ & \\
\hline Shi’a & 1 & \\
\hline Sunni & 1 & \\
\hline Native American / Indigenous & 1 & \\
\hline Pagan / Wiccan & 1 & 1 \\
\hline Shamanism & & 2 \\
\hline Shinto & 1 & \\
\hline Sikh & 2 & 1 \\
\hline Taoist & & 1 \\
\hline Unitarian Universalist & 3 & \\
\hline Unity / Course in Miracles & & 1 \\
\hline Zoroastrian & 1 & \\
\hline
\end{tabular}

${ }^{1}$ This was a "choose all that apply" question. $N$ was larger than 37 ; thus, percentage was not calculated. 
Table 3. Self-Reported Religiosity/Spirituality Over Time

\begin{tabular}{|c|c|c|c|c|}
\hline & Amount Reli & s/Spiritual & & \\
\hline & $\begin{array}{c}\text { Environment } \\
\text { Raised }\end{array}$ & Current & Raised & \\
\hline & $n$ & $n$ & & $n$ \\
\hline Not & 3 & 1 & None & 15 \\
\hline Little Bit & 9 & 8 & A Little & 6 \\
\hline Moderately & 15 & 12 & Moderate & 6 \\
\hline Considerably & 6 & 10 & Considerable & 9 \\
\hline Very & 4 & 6 & Very & 1 \\
\hline Average $(M)$ & 2.97 & 3.32 & & 2.32 \\
\hline
\end{tabular}

\section{Procedures}

Potential participants were directed by a link to an online research website where they saw a short description of the study and were invited to participate if they were willing and qualified. To help determine prequalification, individuals were asked, "Are you over the age of 18 ?" and "Have you come close to death and remember something during the experience (remembrance could be unusual or exceptional, pleasant or unpleasant)?" Those responding in the affirmative were directed to a participant consent form. Upon clicking "I agree to participate," participants were sent an email with the link to continue the study. Once directed to the study, participants again answered the pre-qualification questions (over 18, had an NDE); those responding affirmatively were then directed to the demographics survey, the NDE Scale, and the HSS.

Data were collected through an online site built specifically for this study. The online site included multiple layers of security, including a security certificate (allowing use of the same https used by online banking), a secure server, secure downloading of data, and transfer of raw data from the website to myself as the researcher. The main website administrator completed a confidentiality agreement, as did other individuals who worked with the data, such as a Teaching Assistant. 
Once the data were collected, I used the method described above to determine existence or absence of NDEs among respondents and retained the data for NDEr participants. With these data, I conducted two main analyses. First, I compared the group mean to (a) established means for the measure, and (b) the highest potential score for the HSS to determine presence of a ceiling effect. Second, I compared the data through $t$-tests, using a Bonferroni correction for multiple comparisons, to demographic data to determine if any subgroup differences existed.

\section{Instruments}

Greyson's (1990) revised NDE Scale, along with analysis of a qualitative narrative description of the purported NDE, were used to determine presence of an NDE. The NDE Scale is a 16 -item multiple-choice scale originally created in 1983 that many researchers in the field of near-death studies have used. Each question queries for the presence of a specific characteristic, trait, or element of the NDE and contains three options, one of which is always Neither or No. For example, the first question - the only one slightly modified in 1990 from the original 1983 version-asks, Did time seem to speed up or slow down?, with possible response options of (a) No, (b) Time seemed to go faster than usual or slower than usual, and (c) Everything seemed to be happening all at once, or time stopped or lost all meaning. Participants may score a total from 0 to 32, and mean score for NDErs in Greyson's (1990) study of 183 experiencers was 16.48, whereas the mean score for 63 non-NDErs was 3.79. Additionally, the NDE Scale is comprised of four 4-item subscales, each subscale with a possible score of $0-8$ : Cognitive, Affective, Paranormal, and Transcendental components. During initial creation of the measure, Greyson (1983) established that the NDE Scale had high reliability $(r=.92)$, internal consistency through a strong Cronbach's coefficient alpha (.88), and criterion validity through high correlation with Ring's (1980a) Weighted Core Experience Index $(r=.90)$.

In addition to Greyson's original NDE Scale questions, I included five additional questions. The purpose of the first four of these questions was to enable participants who had had a distressing NDE to so indicate; thus, these items comprised an additional "distressing NDE" (dNDE) component to the instrument. The dNDE questions, and their respective potential responses, were (1) Did you experience a sense of void or nothingness? ([a] Neither, [b] Saw or passed through a place 
of void or nothingness, [c] Clearly entered a place of void or nothingness); (2) Did you experience profound darkness? ([a] Neither; [b] Saw or passed through profound or exceptional darkness, [c] Clearly entered and/or was surrounded by profound or exceptional darkness); (3) Did you feel scared, alone, or frightened? ([a] Neither, [b] Briefly felt scared, alone, and/or frightened, [c] Clearly felt scared, alone, and/ or frightened); and (4) Did you feel as if you were melting away, being torn apart, or somehow disassembled? ([a] Neither, [b] Briefly felt as if I were melting, being torn apart, or disassembled and then felt as if I were being put back together, [c] Clearly felt as if I were melting away, being torn apart, or somehow disassembled). The purpose of the final question was to ascertain the participant's perception of the experience: Did you feel, upon returning, that your experience was due to medications you received or other physiological conditions associated with being close to death? ([a] Experiences were foggy, unclear, and clearly seemed to be associated with a medication or physical reaction related to being close to death, [b] Experience was unusual, and might have been associated with either medications or my physiological experience, [c] Experience was more real than real, I did not have medications, and/or clearly were not associated with my physical state). The data on the additional questions will be reported more in depth at a later time, as greater understanding of this additional dNDE (Greyson \& Bush, 1992; Ring, 1984; Rominger, 2009, 2010) component is a goal of the combined Phase 1 and Phase 2 projects. However, addition of the questions did not seem to substantially reduce the established psychometrics of the measure. In this study the NDE Scale proper demonstrated a moderate to high Cronbach's alpha (.69), as did the NDE Scale with the inclusion of the additional questions (.62). However, these alphas are notably lower than Greyson's (1983) version at a reported .88; I did not find a reported alpha for his revised 1990 scale. For the remainder of this paper, I used only the revised NDE Scale (Greyson, 1990), and all further references to the NDE Scale exclude the five additional items.

Wheat (1991) developed the Human Spirituality Scale to measure spirituality from a non-denominational perspective. The HSS is a 20item self-report instrument based on a 5-point Likert scale ranging from Constantly/Almost Constantly or Strongly Agree (5) to Never/ Almost Never or Strongly Disagree (1). The total possible score on the HSS is 100, and the minimum score is 20. The HSS exhibited high content validity as rated by an independent panel of five judges and high reliability as measured by a Cronbach's alpha of .89 (Wheat, 
1991, p. 85). Construct validity was measured through conducting three studies. The first study demonstrated a significant difference of mean scores between "long term spiritual formation groups" and a control group (Wheat, 1991, p. 93). This study also enabled Wheat to establish normative means for three separate populations: a "high spirituality" group comprised of participants who attended spirituality groups over a number of years $(M=82.26)$, a "sunbathers" group comprised of participants solicited from a public beach and considered to be representative of a normal sample $(M=79.31)$, and a group of "inmates" comprised of participants from a local prison $(M=73.62$; p. 71). The second study demonstrated an alignment of the instrument items with spiritual literature (Wheat, 1991). A third study (Wheat, 1991) demonstrated a strong gender effect as predicted by Wheat's conceptual framework: Men's scores $(M=75.36)$ were significantly lower than women's scores $(M=82.83 ; p<.001)$, but a two-way analysis of variance performed on sex and age revealed no significant difference between older and younger men and women.

Wheat (1991) additionally established three factors within the HSS: Larger Context, Awareness of Life, and Compassion. Factor 1, Larger Context, included 10 questions such as Being truthful is important to a successful life, I find meaning in life by creating close relationships, I experience a feeling of being whole and complete as a person, and It is important that each of us find meaning in our lives. Factor 2, Awareness of Life, included four questions such as I experience a sense of the sacred in living things, I experience a sense of connection with other living things, and I set aside time for personal reflection and growth. Factor 3, Compassion, included six questions such as I value the relationship between all living things, We should give to others in need, It is important that we be sensitive to pain and suffering, and All forms of life are valuable. Factors were established through typical iterations of factorial analysis as questions were eliminated from the questionnaire to create a coherent measure.

\section{Results}

Regarding NDE Scale scores, the 37 participants scored a total mean of $13.27(S D=5.15)$ with scores ranging from 7 to 26 . Generally, the scores for the four subscales were consistent: Cognitive Component $(M=3.70, S D=1.66)$, Affective Component $(M=3.43, S D=2.28)$, Paranormal Component $(M=3.22, S D=1.57)$, and Transcendent 
Component $(M=3.70, S D=2.37)$. Regarding total HSS score, with potential range of $20-100$, the mean was $79.49(S D=8.79)$ and actual range of 59-91. Regarding HSS factor scores, Factor 1: Larger Context, with potential range of $10-50$, the mean was $40.11(S D=4.64)$ and actual range 27-47; Factor 2: Awareness of Life, with potential range of $4-20$, the mean was $13.38(S D=3.41)$ and actual range $6-19$; and Factor 3: Compassion, with potential range of 6-30, the mean was $26.00(S D=2.68)$ and actual range $20-30$.

With regard to my first research goal to explore a possible ceiling effect with the HSS, Figure 1 shows a scattergram of total HSS scores. Because nine points remained between the highest scores of 91 and the potential total of 100 and because respondents' scores did not concentrate at the top of the scale, the instrument did not demonstrate a ceiling effect with the sample of 37 NDErs in this study.

With regard to my second research goal to explore the relationships between HSS and NDE Scale scores, Figure 1 also shows a scattergram of total NDE Scale scores, and Table 4 shows correlations between both instruments' total and subscale/factor scores. Results

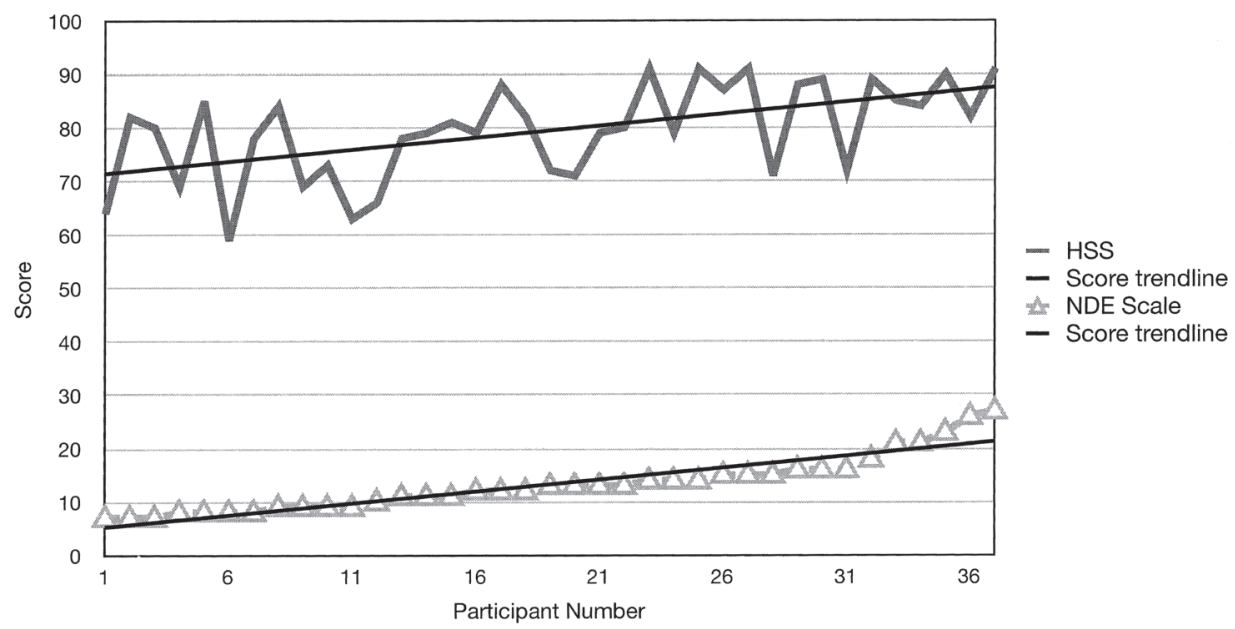

Figure 1. Scattergram of total HSS and NDE Scale scores of NDEr participants $(N=37)$. 
Table 4. Correlations Between NDE Scale and HSS Scores

\begin{tabular}{|c|c|c|c|c|c|c|c|c|}
\hline & \multicolumn{8}{|c|}{ HSS } \\
\hline & \multicolumn{2}{|c|}{ Total } & \multicolumn{2}{|c|}{ Larger Context } & \multicolumn{2}{|c|}{$\begin{array}{c}\text { Awareness } \\
\text { of Life }\end{array}$} & \multicolumn{2}{|c|}{ Compassion } \\
\hline & $r$ & $p$ & $r$ & $p$ & $r$ & $p$ & $r$ & $p$ \\
\hline $\begin{array}{l}\text { NDE Scale } \\
\text { Total }\end{array}$ & .527 & $.001^{* *}$ & .454 & $.005^{* *}$ & .595 & $<.001^{* *}$ & .186 & .272 \\
\hline Cognitive & .181 & .284 & .134 & .429 & .250 & .135 & .044 & .798 \\
\hline Affective & .365 & $.026^{*}$ & .243 & .148 & .471 & $.003^{* *}$ & .293 & .053 \\
\hline Paranormal & .361 & $.028^{*}$ & .421 & $.009 * *$ & .317 & .056 & .053 & .755 \\
\hline $\begin{array}{l}\text { Transcen- } \\
\text { dental }\end{array}$ & .427 & $.008^{* *}$ & .380 & $.021 * *$ & .454 & $.005^{* *}$ & .166 & .326 \\
\hline
\end{tabular}

Note: $N=37 .{ }^{*} p<.05 ;{ }^{* *} p<.01(2$-tailed $)$.

indicate that all correlations were positive; that out of 20 possible correlations, 10 were significant; and that of the 10 non-significant correlations, 8 involved two dimensions: the NDE Cognitive subscale and the HSS Compassion factor. Thus, in this study the NDE Scale and HSS were positively correlated consistently or predominantly with regard to total scores; affective, paranormal, and transcendent aspects of NDEs; and larger context and awareness of life factors of spirituality. Among the 37 participants in this study, those who reported relatively deeper NDEs and those who reported deeper transcendental aspect in their NDEs also reported overall greater spirituality and specifically a sense of larger context in and awareness of life; those who reported deeper affect in their NDEs also reported overall greater spirituality and awareness of life; and those who reported relatively deeper paranormal aspects in their NDEs also reported overall greater spirituality and a sense of larger context in life. Participants who reported greater cognitive NDE aspects did not report greater overall or specific aspects of spirituality, and those who reported deeper NDEs, either overall or with regard to specific aspects, did not report higher levels of compassion.

I also undertook some further exploratory follow-up analyses. In an exploration of both scale scores and participant demographics, results were that both scores were significantly correlated, on some level, with age, sex, and country; see Table 4. Thus, older participants 
tended to report more overall NDE phenomena and affective and transcendent NDE components as well as greater overall spirituality, perceiving a larger context in life, greater awareness of life, and greater compassion. Women tended to report more overall NDE phenomena and affective and transcendent components as well as greater overall spirituality, perceiving a larger context in life, greater awareness of life, and greater compassion. U.S. participants reported more overall NDE phenomena and affective and transcendent NDE components as well as greater awareness of life.

A Spearman rho correlation-for use with ordinal data-revealed another significant finding: Education was correlated with a number of demographic variables, including age $(r=.43, p<.008)$, biological sex ( $r=.43, p<.008$, males $M=5.35$ [between Associates and Bachelor's degree], females $M=6.59$ [between Bachelor's and Master's degree]), and the degree of current religiosity/spirituality $(r=.46, p<.004)$. Education was also correlated with the HSS $(r=.36, p<.031)$, the NDE Scale $(r=.52, p<.001)$, and the Transcendent component of the

Table 5. Correlation Between Demographic Variables and Scores on NDE Scale and HSS

\begin{tabular}{|c|c|c|c|c|c|c|}
\hline & \multicolumn{6}{|c|}{ Demographic } \\
\hline & \multicolumn{2}{|c|}{ Age } & \multicolumn{2}{|c|}{ Sex } & \multicolumn{2}{|c|}{ Country } \\
\hline & $r$ & $p$ & $r$ & $p$ & $r$ & $p$ \\
\hline $\begin{array}{l}\text { NDE Scale } \\
\text { Total }\end{array}$ & .577 & $<.001^{* *}$ & .517 & $.001^{* *}$ & .534 & $.001^{* *}$ \\
\hline Cognitive & -.176 & .298 & .101 & .552 & .094 & .579 \\
\hline Affective & .528 & $.001^{* *}$ & .546 & $<.001^{* *}$ & .522 & $.001^{* *}$ \\
\hline Paranormal & .312 & .060 & .187 & .268 & .126 & .458 \\
\hline $\begin{array}{l}\text { Transcen- } \\
\text { dental }\end{array}$ & .661 & $<.001^{* *}$ & .403 & $.013^{*}$ & .507 & $.001 * *$ \\
\hline HSS Total & .637 & $<.001 * *$ & .586 & $<.001^{* *}$ & .259 & .121 \\
\hline $\begin{array}{l}\text { Larger } \\
\text { Context }\end{array}$ & .489 & $.002^{* *}$ & .393 & $.016^{*}$ & .114 & .502 \\
\hline $\begin{array}{l}\text { Awareness } \\
\text { of Life }\end{array}$ & .621 & $<.001^{* *}$ & .638 & $<.001^{* *}$ & .528 & $.001^{* *}$ \\
\hline Compassion & .455 & $.005^{* *}$ & .431 & $.008^{* * *}$ & -.017 & .919 \\
\hline
\end{tabular}

Note: $N=37 .{ }^{*} p<.05 ;{ }^{* *} p<.01$ (2-tailed). 
Table 6. Comparison of Total HSS Scores between NDErs and Wheat's (1991) Participants

\begin{tabular}{lcccccc}
\hline & $M$ & $S D$ & $t$ & $d f$ & $p$ & $d$ \\
\cline { 2 - 6 } NDErs & 79.49 & 8.79 & & & & \\
Wheat (1991): & & & & & & \\
Inmates & 73.62 & $n d$ & 4.06 & 36 & $<.001^{* *}$ & 1.35 \\
$\begin{array}{l}\text { Sunbathers } \\
\begin{array}{l}\text { High Spiritu- } \\
\text { ality Group }\end{array}\end{array}$ & 79.31 & $n d$ & 0.12 & 36 & .90 & 0.04 \\
\hline
\end{tabular}

Note: Wheat (1991) did not report standard deviations for his three comparison groups; thus " $n d "$ designates no data. * $p<.002$ (2-tailed).

NDE Scale $(r=.44, p<.007)$. Thus, in this study the more educated participants tended to be older; to be female; to report more NDE phenomena, especially those elements that were transcendent in nature; and to report higher overall spirituality.

I also was interested in exploratory analysis of various scale score data. For such comparisons, the most rigorous statistic for which the data met all analysis assumptions was the $t$-test. Because I would be using multiple $t$-tests, I used a Bonferroni adjustment to establish the alpha level necessary for significance; the adjustment (.05 divided by the number of $t$-tests run, which was 25) yielded the criterion $p<.002$. As no norms exist for effect size criteria in NDE research, I adopted Cohen's (1969) cautious suggestion for $d$ minimum thresholds of .2 for small, .5 for medium, and .8 for large effect.

I was interested in how the NDErs' HSS scores in this study compared to Wheat's original samples. Results are displayed in Table 6. NDErs in this study scored significantly higher than Wheat's inmates with a large effect, not significantly higher than Wheat's sunbathers with no effect, and not significantly lower than Wheat's high spirituality group with a medium effect.

\section{India and the United States}

As demographic analysis indicated differences by country, participation by individuals from India $(n=19)$ and the U.S. $(n=12)$ presented a unique opportunity for exploratory comparison. Results of indepen- 
Table 7. Comparison of India and U.S. NDEr Data

\begin{tabular}{|c|c|c|c|c|c|c|c|c|}
\hline & \multicolumn{2}{|c|}{ India } & \multicolumn{2}{|c|}{ U.S } & \multirow[b]{2}{*}{$t$} & \multirow[b]{2}{*}{$d f$} & \multirow[b]{2}{*}{$p$} & \multirow[b]{2}{*}{$d$} \\
\hline & $M$ & $S D$ & $M$ & $S D$ & & & & \\
\hline Age (in years) & 28.26 & 8.27 & 42.08 & 13.56 & & & & \\
\hline $\begin{array}{l}\text { Age at NDE (in } \\
\text { years) }\end{array}$ & 21.58 & 8.13 & 16.25 & 8.45 & & & & \\
\hline NDE Scale & 11.53 & 3.73 & 17.58 & 5.47 & 3.67 & 29 & $<.001^{* *}$ & 1.35 \\
\hline Cognitive & 3.84 & 1.68 & 4.00 & 1.60 & .26 & 29 & .80 & .10 \\
\hline Affective & 2.47 & 1.84 & 5.17 & 2.29 & 3.61 & 29 & $<.001^{* *}$ & 1.33 \\
\hline Paranormal & 3.05 & 1.51 & 3.67 & 1.83 & 1.02 & 29 & .32 & .38 \\
\hline Transcendent & 2.16 & 1.80 & 4.75 & 2.22 & 3.57 & 29 & $<.001^{* *}$ & 1.32 \\
\hline HSS & 78.42 & 8.08 & 83.42 & 6.97 & 1.77 & 29 & .08 & .65 \\
\hline Larger Context & 40.26 & 5.00 & 41.08 & 2.78 & .68 & 29 & .50 & .25 \\
\hline $\begin{array}{l}\text { Awareness } \\
\text { of Life }\end{array}$ & 13.11 & 3.46 & 15.00 & 2.95 & 4.12 & 29 & $<.001^{* *}$ & 1.52 \\
\hline Compassion & 26.11 & 2.60 & 26.42 & 2.87 & .05 & 29 & .96 & .02 \\
\hline
\end{tabular}

Note: $n=19$ participants from India and 12 from U.S.; * $p<.002$ (2-tailed).

dent samples $t$-tests comparing these two subgroups appear in Table 7.

Compared to participants from India on the NDE Scale, U.S. participants scored significantly higher with a large effect on the total score, the Affective component, and the Transcendental component, but not significantly higher with no effect on the Cognitive component and not significantly higher with a small effect on the Paranormal component. Regarding the HSS, U.S. participants did not score significantly higher with a medium effect on the total score, with a small effect on the Larger Context factor, and with no effect on the Compassion factor, but they scored significantly higher with a large effect on the Awareness of Life factor.

HSS scores of participants in this study from the U.S. and India were compared with scores of the sample populations Wheat (1991) used when creating his original instrument. Results are shown in Table 8. Compared to Wheat's inmates, NDErs from India did not score significantly higher and U.S. NDErs did, but the effect size in both cases was large. Compared to Wheat's sunbathers, Indian NDErs did 
Table 8. Comparison by Country of HSS Total Scores to Wheat's (1991) Original Sample

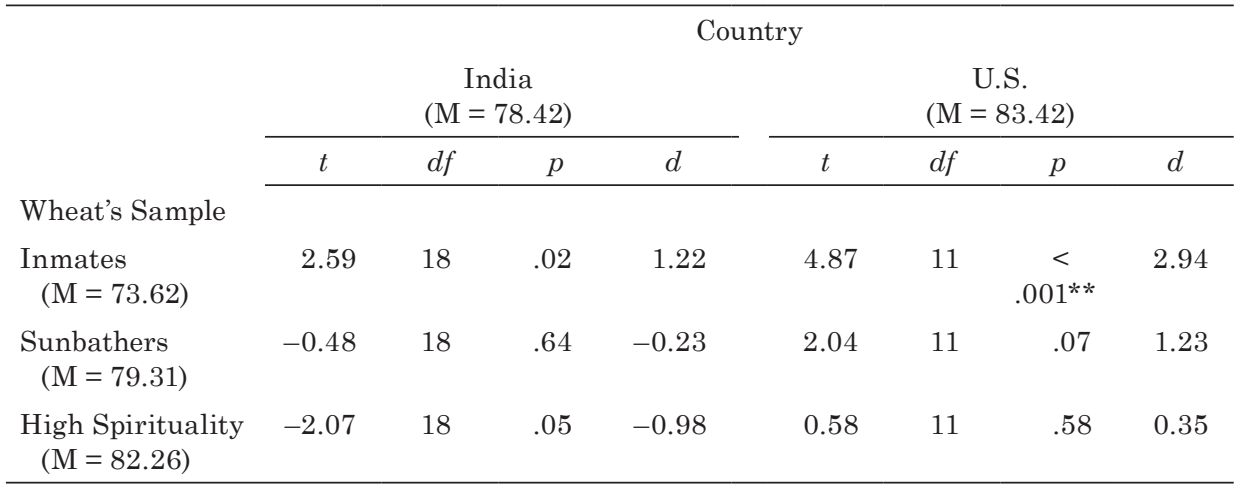

Note: $n=19$ participants from India and 12 from U.S.; * $p<.002$ (2-tailed).

not score significantly lower, and with a small effect size, and U.S. NDErs did not score significantly higher, though with a large effect size. Compared to the high spirituality group, Indian NDErs did not score significantly lower, but with a large effect size, and U.S. NDErs did not score significantly higher, with a small effect size.

\section{Participants' Sex}

Considering that demographic analysis had indicated a difference by sex in NDE Scale and HSS total and subscale scores and that the participant population included a fairly even distribution of men and women, post hoc analysis also allowed comparison of these two groups. Results are shown in Table 9.

Because the statistical difference between men and women was so strong, I chose to visually dissect the participants' numbers a bit further; see Table 10.

If all countries and participant sex were equally represented, then the influence of the variables would be equally distributed. However, if either the countries or the participant sex are not equally represented, then the variable with the larger than expected representation may hold more weight during statistical analysis. According to a one-sample Chi-Square Goodness of Fit testing, the Countries are not equally represented $(X=73.49, d f=7, p<.001)$. A one-sample binomial test to determine if the categories of Sex occur with equal probability, 
Table 9. Comparison by Sex of HSS and NDE Scale Scores

\begin{tabular}{lcccccc}
\hline & Men & Women & $t$ & $d f$ & $p$ & $d$ \\
\cline { 2 - 6 } Mean age & 26 years & 40 years & & & & \\
At NDE & 18 years & 21 years & & & & \\
Mean NDE Scale & 10.85 & 16.12 & 3.58 & 35 & $<.001^{* *}$ & -1.18 \\
Cognitive & 3.55 & 3.99 & -.60 & 35 & .552 & -0.20 \\
Affective & 2.30 & 4.76 & -3.86 & 35 & $<.001^{* *}$ & -1.30 \\
Paranormal & 2.95 & 3.53 & -1.13 & 35 & .268 & -0.38 \\
Transcendental & 2.05 & 3.94 & -2.60 & 35 & .013 & -0.88 \\
Mean HSS & 74.80 & 85.00 & 4.28 & 35 & $<.001^{* *}$ & -1.41 \\
Context & 38.45 & 42.06 & 2.53 & 35 & $<.020$ & 0.84 \\
Awareness of & 11.40 & $15 / 71$ & 4.9 & 35 & $<.001^{* *}$ & 1.62 \\
Life & 24.95 & 27.24 & 2.83 & 35 & $<.008$ & 0.93 \\
Compassion & & & & & & \\
\hline
\end{tabular}

Note: $n=20$ men and 17 women; ${ }^{*} p<.002$ (2-tailed).

Table 10. Sample Size of Male and Female Participants by Country

\begin{tabular}{lcc}
\hline & Male & Female \\
\cline { 2 - 3 } India & 13 & 6 \\
United States & 3 & 9 \\
Other & 4 & 2 \\
\hline
\end{tabular}

however, revealed no significant difference from the expected probability $(R=.33, p=.74)$. Thus, it is possible that the factor of country contributes more to differences between male and female NDE Scale and HSS scores than the factor of sex. However, when a multivariate analysis of variance was run to determine interaction effects by country and sex, the interaction effect was not significant, likely due to the small $N$ and low power (HSS: $F=1.189, p=.285, d f=1$, power $=.183$; NDE Scale: $F=1.692, p=.204, d f=1$, power $=.241)$. Even when the 
countries are grouped into India, U.S. and other (thus, only 3 groups), the interaction effect remained non-significant with low power (HSS: $F=.491, p=.617, d f=2$, power $=.123$; NDE Scale: $F=1.607, p=.217$, $d f=2$, power $=.314$ ).

\section{Age}

As noted above, participant age was correlated with HSS total score, with all three HSS factor scores, with NDE Scale total score, and with two of the four NDE Scale component scores: Affective and Transcendent. When grouped, the majority of participants (67\%) were between 18-35 years old, and most participants (81\%) had their NDEs between 11-30 years old. Because post-hoc analysis by age would result in a small $n$ within each age group, leading to a low effect size and power, no such analysis was pursued.

\section{Atheist/Agnostic}

A unique aspect of this study was the presence of four participants who self-reported as atheist or agnostic - two categories that were not differentiated in the survey. As I have not seen discussion of people representing this demographic in any NDE literature prior to this study, it may be important for future research to describe these four individuals in particular, acknowledging that such description is quite speculative because of the low $n$. Although the low $n$ precludes statistical analysis, descriptive data point to possible foci for future research.

The average age of this group was 24.5 , and average age at time of NDE was 20.25 , only 4.25 years prior. Three were male, and one was female. One was from India, one from the Ukraine, and two from the U.S. Two reported having some college education, one reported having an Associate's Degree, and one a Bachelor's Degree. One reported being disabled, and three did not. Two reported an annual family income range of $\$ 25,001-\$ 50,000$; the other two reported a range of $\$ 100,001-\$ 125,000$. Three indicated this income supported four individuals, whereas one person indicated it supported only one individual. All four were raised in a religious or spiritual tradition. One indicated having been raised in almost every major tradition including Lutheran, Roman Catholic, Hindu, Vajrayana, Shinto, Confucian, Sikh, Muslim: Shi'a, Jewish: Kabbalah, Pagan and Wiccan, Unitarian Universalist, and Eclectic. One participant indicated Hindu: Other. Another indicated Muslim: Suni. The last participant indicated 
Catholic and Unitarian Universalist. Participants reported a mean degree of religiosity/spirituality of their environments of upbringing to be 3.25 (out of 5). All indicated they were not currently practicing a religious/spiritual tradition, and the reported mean degree of religiosity/spirituality was 2.75 (out of 5). Their reported mean degree of difference between religiosity/spirituality of how they were raised and their current beliefs was 3.5 (out of 5). The mean NDE Scale total score for this subgroup was 11 with a range of 9-13, and the mean HSS total score was 75-a score between the inmates' scores and the sunbathers' scores in Wheat's (1991) study.

\section{Discussion}

First and foremost, it should be noted that due to low sample size, this study became exploratory in nature, pointing not toward firm conclusions but toward trends for future researchers to consider. Statistical findings should be viewed in light of the power and effect sizes noted in the respective sections, particularly once participants were divided into smaller groups based on various demographic variables. Thus, results from comparing participants from India and the U.S. or comparing men and women should be considered trends, and I highly recommend further research with NDErs that involves administration of instruments to measure spirituality such as the HSS.

Considering the above caveat, the main goal of this study was to determine if a ceiling effect was present when the HSS was used with individuals who report having had an NDE. Considering the current sample's scores, I did not find a ceiling effect; thus the HSS may remain a viable option for use within the NDE population.

A second goal of this study was to determine a relationship between the NDE Scale and the HSS. Results indicated a strong positive correlation between the two measures. The weakest connection was Factor 3: Compassion, which contains questions such as I value the relationship between all living things, We should give to others in need, It is important that we be sensitive to pain and suffering, and All forms of life are valuable. I am unsure at this time why this factor in particular might demonstrate little correlation with the NDE Scale and suggest further research involving use of the HSS. In addition to the Compassion factor, the Cognitive component of the NDE Scale demonstrated nonsignificant findings. However, when discussing validity Greyson (1983) noted that the Cognitive component was the component least correlated with Ring's Weighted Core Experience Index (WCEI; 1980a) 
as well as the component least correlated with the NDE Scale as a whole. Whereas both correlations were still moderately high $(r=.63$ and $r=.72$ respectively; 1983, pp. 371-373), the trends demonstrated by Greyson (1983) align with the findings of nonsignificance in the current study. Together the Compassion factor and Cognitive component demonstrate eight of the nine nonsignificant findings between the NDE Scale and the HSS (see Table 4).

A post-hoc goal of this study was to explore relationships between various demographic groups present within the sample population. Higher scores on both the NDE Scale and HSS tended to be associated with U.S. vs. Indian, female vs. male, older vs. younger, and more vs. less educated participants. The U.S. participants tended to be older, more educated females and the Indian participants to be younger, less educated males. The only reference to any of these four factors in Wheat's study were his finding of higher HSS scores among females. Due to a low $n$ I was not able to conduct analyses that would fully tease out the relative contribution of each factor, and thus it remains for future researchers to determine the extent to which each of these factors plays the greater contributing role. However, cultural differences in particular as noted in this study should be further explored. It is possible the differences could be due to age, sex, language (the HSS was delivered in English only), or even inherent ontological differences between the two cultures; not enough is known at this time to support a strong conclusion.

Another demographic variable of note within this study was the various religious and spiritual affiliations that participants indicated. Table 2 displays the variety of religious and spiritual traditions from which participants came in their upbringings, as well as the variety of traditions to which they have migrated. It is possible factors other than the NDE caused these shifts; however, it is interesting to note that participants reported migrating away from Christian (Catholic and Protestant), Hindu, and Muslim traditions without a corresponding rise in current participation in other traditions. This result corresponds to findings by Ring (1984) and others that NDErs tend to become more non-religiously-affiliated spiritual than religious.

Fourth, a unique aspect of this study was the inclusion of four individuals who self-reported to be atheist or agnostic. Little prior research exists regarding NDErs who are either raised or become atheist or agnostic. These four individuals tended to be younger, to have had their NDEs only a few years prior, and to have had both lower NDE Scale and HSS scores. It is possible, due to the short time be- 
tween the reported NDE and this study, that these individuals are in a process of "integrating" or assimilating their experience. However, that position would assume that one must necessarily become more spiritual after the NDE if one fully integrates the experience, which may not be the case. It could be that, due to how NDErs are portrayed in the media, few atheist or agnostic NDErs - similar perhaps to those who have a distressing experience-wish to come forward and share the experience. The area of atheist or agnostic NDErs is ripe for further research.

Finally, this study is important regarding participant recruitment. Every intention was made to recruit participants through social networking and online sites. I thought that by recruiting in this manner the participant population might include individuals who (a) have had NDEs but do not attend International Association for Near-Death Studies or other similar meetings and (b) have had NDEs not usually found within mainstream NDE literature. Most participants were recruited through Facebook and Craigslist, two online sites; most had NDEs similar to those described in mainstream literature; and, although participant averages could have been just over 7 on the NDE Scale, the average score was actually 13.27, a full standard deviation above the cut-off score of 7 for determining the presence of an NDE. However, consider that the project was U.S.-based, a unique subset of participants was individuals outside the U.S., particularly from India. Many more international individuals participated than I had anticipated. Additionally, the group from India was much younger than I had envisioned, attesting to the early ages at which people may have NDEs and participate in studies. Based on results of both this study and those of Jeffrey Long (2010), online recruitment appears to be a viable means of recruiting participants for studies focused on NDEs and particularly offers a unique opportunity for cross-cultural research on the topic.

\section{Conclusion}

So long as a researcher acknowledges the difference between male and female scores, the HSS remains a viable option for use with the NDE population. The HSS did not seem to demonstrate a ceiling effect and did demonstrate a positive correlation with the NDE Scale. Future research may include use of additional spirituality scales to determine the most appropriate measure(s) for use with this population. 


\section{References}

Fenwick, P., \& Fenwick, E. (1996). The near-death experience. In P. Badham \& P. Ballard (Eds.), Facing death: An interdisciplinary approach (pp. 133-153). Cardiff, United Kingdom: University of Whales Press.

Greyson, B. (1983). The Near-Death Experience Scale: Construction, reliability, and validity. Journal of Nervous and Mental Disease, 171(6), 369-375.

Greyson, B. (1990). Near-death encounters with and without near-death experiences: Comparative NDE Scale profiles. Journal of Near-Death Studies, 8(3), 151-161.

Greyson, B. (1985). A typology of near-death experiences. American Journal of Psychiatry, 142, 967-969.

Greyson, B., \& Bush, N. (1992). Distressing near-death experiences. Psychiatry, 55(1), 95-110.

Groth-Marnat, G., \& Summers, R. (1998). Altered beliefs, attitudes, and behaviours following near-death experiences. Journal of Humanistic Psychology, 38(3), 110-125.

Holden, J. M., Greyson, B., \& James, D. (Eds.). (2009). The handbook of neardeath experiences: Thirty years of investigation. Santa Barbara, CA: Praeger/ ABC-CLIO.

Long, J., (with Perry, P.) (2010). Evidence of the afterlife: The science of neardeath experiences. New York, NY: HarperCollins.

MacDonald, D. A. (1997). The development of a comprehensive factor analytically Derived measure of spirituality and its relationship to psychological functioning. Doctoral dissertation. University of Windsor, Windsor, Ontario, Canada.

MacDonald, D. A., Kuentzel, J. G., \& Friedman, H. L. (1999). A survey of measures of spiritual and transpersonal constructs: Part two-Additional instruments. Journal of Transpersonal Psychology, 31(2), 155-177.

Moody, R. A., Jr. (1975). Life after life. New York, NY: Bantam Books.

Musgrave, C. (1997). The near-death experience: A study of spiritual transformation. Journal of Near-Death Studies, 15(3), 187-201.

Ring, K. (1980a). Life at death: A scientific investigation of the near-death experience. New York, NY: Quill.

Ring, K. (1980b). Religious aspects of near-death experiences: Some research findings and their implications. Journal of Religion and Psychical Research, $3(2), 105-114$.

Ring, K. (1984). Heading toward omega: In search of the meaning of the neardeath experience. New York, NY: Quill.

Rominger, R. (2009). Exploring the integration of near-death experience aftereffects: Summary of findings. Journal of Near-Death Studies, 28(1), 3-34.

Rominger, R. (2010). Postcards from heaven and hell: Understanding the neardeath experience through art. Art Therapy: Journal of the American Art Therapy Association, 27(1), 18-25.

Sahlman, J. M., \& Norton, M. C. (1998). The meaning and intensity of the neardeath experience. Journal of Near-Death Studies, 17(2), 101-110. 
Twemlow, S. W., \& Gabbard, G. O. (1984). The influence of demographic/psychological factors and preexisting conditions on the near-death experience. Omega, 15(3), 223-235.

Wheat, L. W. (1991). Development of a scale for the measurement of human spirituality. Unpublished doctoral dissertation, University of Maryland College Park. 